\title{
SUBSTITUTION OF NTO BY HTP IN A BIPROPELLANT RCS
}

\author{
U. C. Oliveira, \\ Institute of Aeronautics and Space \\ CTA/IAE/ASE -12228-904 \\ São José dos Campos-SP, Brazil \\ ulisses@iae.cta.br \\ D. J. F. Villas Bôas, \\ Institute of Aeronautics and Space \\ CTA/IAE/ASE -12228-904 \\ São José dos Campos-SP, Brazil \\ danton@iae.cta.br

\begin{abstract}
The present article presents some theoretical considerations about the implications due the change of the oxidizer in a bipropellant propulsion system. Preliminary analysis conducted on the NTO/UDMH $400 \mathrm{~N}$ engine of a roll control system shows that this engine could be capable of operation with HTP90 without significant modification in the design. The new propellant combination is less toxic, can be handled more easily, has a wider operational temperature range, and yields a more amenable thermal environment from the combustion down to the exhaustion. Even with a decrease in liquid film cooling, the HTP90/UDMH engine would present a satisfactory reduction of the combustion chamber temperature and approximately the same performance level of the original NTO/UDMH engine.

Keywords: Reaction Control Systems, Auxiliary Propulsion Systems, Rocket Propellants, Hydrogen Peroxide.
\end{abstract}

\section{INTRODUCTION}

The nature of propellants in a propulsion system determines largely its complexity and cost (Oliveira, 2000a). Therefore, the proper choice of the propellant combination could result in a intrinsically simpler, more reliable, and cheaper propulsion system. If, in the past, designing for maximum performance and minimum weight led to the use of cryogenic and toxic propellants (London, 1994; Oliveira, 2000b), the recent environmental and economic concerns arose the interest in other alternatives (Hurlber et al., 1998; Andrews, 1990; Oliveira, 2000a; Truax, 1999).

The present article presents some theoretical considerations about the implications due the change of the oxidizer in a bipropellant auxiliary propulsion system. In the original $400 \mathrm{~N}$-thrust system (Anon., 1992), which is used for roll control of a solid propulsion launch vehicle, the fuel is unsymmetrical dimethylhydrazine, and the oxidizer is nitrogen tetroxide (NTO). Although both components are toxic and hazardous, NTO offers higher risks, and its use must be, as much as possible, avoided. The proposal in study (Oliveira, 2002) consists in substituting NTO by high test peroxide (HTP). It is expected that the more amenable handling and storage characteristics of the HTP, in addition to the less severe combustion conditions obtained with such oxidizer, result in a propulsion system more affordable and, at least, less dangerous to the environment and personnel.

In order to substantiate the further discussion, some general definitions and specific information about propellants, thrust chamber materials, and film-cooling technique will be presented in next sections.

\section{PROPELLANTS}

A bipropellant propulsion system is affected not only by the nature of the propellant components, but also by their proportions in the composition of the propellant, as will be shown next.

\section{Hydrazine Fuels}

Traditionally, auxiliary bipropellant propulsion systems use combinations of nitrogen tetroxide (NTO) and hydrazine $\left(\mathrm{N}_{2} \mathrm{H}_{4}\right)$ or one of its derivatives, namely, monomethyl-hydrazine (MMH), unsymmetrical dimethyl-hydrazine (UDMH), and Aerozine-50 (a 50\%: $50 \%$ mixture of hydrazine and UDMH). All hydrazines are toxic substances, but MMH is the most toxic when inhaled, and UDMH the least toxic. Hydrazine is the densest, and UDMH has a intermediary density. In combinations with $\mathrm{NTO}$, pure $\mathrm{N}_{2} \mathrm{H}_{4}$ gives only slightly higher specific impulses than MMH or UDMH. In general, pure $\mathrm{N}_{2} \mathrm{H}_{4}$ presents worse thermal characteristics (heat-transfer properties, liquid temperature range) than its related substances.

The propellant standard of the international aerospace industry is the pair NTO/MMH, certainly due to the higher mass density of MMH. Nevertheless, the pair NTO/Aerozine-50 continues to be largely used in western countries, and the Russian engineers use preferentially the pair NTO/UDMH.

\section{Nitrogen Tetroxide}

Nitrogen tetroxide (NTO) has chemical formula $\mathrm{N}_{2} \mathrm{O}_{4}$. It consists principally of the tetroxide in equilibrium with a small amount of nitrogen dioxide $\left(\mathrm{NO}_{2}\right)$. The purified grade contains less than 0.1 per cent water. When dry, it is not corrosive to mild steel at normal temperatures, but it readily absorbs moisture from air. Nitrogen tetroxide has a characteristic reddish-brown color in both liquid and gaseous phases. It became the storable liquid oxidizer of choice from the late 1950's, although its liquid temperature range is narrow and it is easily frozen or vaporized. Nitrogen tetroxide is moderately reactive. It is hypergolic with many fuels (including hydrazine and its derivatives) and can cause 
spontaneous ignition with many common materials, such as paper, leather, and wood. It is very toxic and carcinogenic, requiring special handling and use procedures.

\section{High Test Peroxide}

Concentrated hydrogen peroxide aqueous solution is commonly called high test peroxide or HTP. It is storable, nontoxic and has other advantages as well (Andrews, 1990). It is very dense and has a very low vapor pressure. It is relatively inexpensive because it is an ordinary industrial chemical rather than a dedicated rocket propellant (Jeff, 1998). It is a good regenerative coolant and has excellent characteristics to be used in secondary injection for thrust vector control. Although some special precautions must be taken to prevent it from decomposing in the presence of impurities, it is a stable substance, and once those precautions have been taken it essentially handles like water (Jeff, 1998).

Since HTP can be used as both an oxidizer and a monopropellant, a number of beneficial design simplifications and variable operational scenarios are possible. The decomposition products can be used as the oxidizer in a bipropellant system, for thrust in monopropellant mode, and as the working fluid for tank pressurization. The dual mode operation (mono- or bipropellant) enables wide thrust variability (Oliveira, 2000a).

Combinations of HTP and hydrazine and its derivatives form pairs that will readily ignite without benefit of any igniter or ignition promoter (Bloom et al., 1950). They are characterized by reasonably low combustion and exhaust temperatures and high density of working gases.

\section{Mixture Ratios and Average Mass Density}

For liquid propulsion systems, the tanks are sized after determining the propellant load because the tanks are the largest and heaviest components. For bipropellant systems, the oxidizer and fuel requirements are determined from

$$
K_{m}=\frac{m_{o}}{m_{f}},
$$

where $K_{m}$ is the oxidizer/fuel mass mixture ratio needed to deliver the required specific impulse, $m_{O}$ is the oxidizer mass, and $m_{f}$ is the mass of the fuel.

The Eq. (1) could be rewritten as

$$
K_{m}=\frac{\rho_{o}}{\rho_{f}} \frac{V_{o}}{V_{f}},
$$

where $V_{o}$ and $V_{f}$ are the oxidizer and fuel volumes, respectively, $\rho_{f}$ is the fuel mass density, and $\rho_{o}$ is the oxidizer mass density.

For any given mixture ratio $K_{m}$, the bulk mass density $^{1}$ of a propellant combination $\rho_{p}$ can be determined from the mass density of the components. It

\footnotetext{
${ }^{1}$ This term is preferable to the normally used bulk density, although the better designation would be average volumic mass, in accordance with the most recent recommendations (Taylor, 1995).
}

is defined as the mass of the fuel and oxidizer, divided by the sum of their volumes (Oliveira, 2000b):

$$
\rho_{p}=\left(K_{m}+1\right)\left(\frac{K_{m}}{\rho_{o}}+\frac{1}{\rho_{f}}\right)^{-1},
$$

Tank volumes are calculated from propellant volumes loaded into each tank, plus reasonable allowances for ullage (gas volume in the propellant tank, approximately 5\%), design margin, and propellant remaining in each tank because of trapped liquids or uncertainties in loading and performance.

The mixture ratio is a critical parameter in propulsion system sizing; therefore, its selection is the first step in determining the propellant quantities for a given set of propulsion-system requirements (total impulse). Very often, we select the mixture ratio for system benefits other than just maximum $I_{s p}$. Consider the example of storable-bipropellant systems using NTO/UDMH for low-thrust systems. They almost always use a mixture ratio of 1.827 because this value results in tanks of equal size. Equal sizing simplifies tank manufacturing, packaging of propulsion systems (configuration layout), integration, and cost. Table 1 shows the values of $K_{m}$ for which are obtained equal oxidizer and fuel volumes, at $298.15 K$, for propellant pairs of interest to this analysis.

Table 1: Mass mixture ratios for equal component volumes (at 298.15 K).

\begin{tabular}{|c|c|c|c|c|}
\hline & $\mathrm{N}_{2} \mathrm{H}_{4}$ & UDMH & MMH & $\rho_{o}\left(\mathrm{~kg} / \mathrm{m}^{3}\right)$ \\
\hline \hline NTO & 2.1467 & 1.8274 & 1.6483 & 1434.35 \\
HTP90 & 2.0757 & 1.7670 & 1.5938 & 1386.94 \\
$\rho_{f}\left(\mathrm{~kg} / \mathrm{m}^{3}\right)$ & 1003.7 & 784.90 & 870.23 & --- \\
\hline
\end{tabular}

The $K_{m}$ ratio at which the engine is operating is defined as:

$$
K_{m}=\frac{\dot{m}_{o}}{\dot{m}_{f}},
$$

where $\dot{m}_{o}$ and $\dot{m}_{f}$ are the oxidizer and the fuel mass flow rates. The maximum theoretical value of the characteristic exhaust velocity, $c^{*}$, is achieved at a specific mixture ratio. This optimum mixture ratio depends on the particular propellant combination. Usually, the mixture ratio is chosen so that the reaction products have the maximum achievable value of $T_{c} / \mathcal{M}$ and thus the highest possible specific impulse (Oliveira, 2000b). In some situations a different mixture ratio results in a better overall system. For a volumeconstrained vehicle with a low density fuel, significant reductions in vehicle size can be achieved by shifting to an oxidizer-rich mixture ratio. In that case, the losses in specific impulse are more than compensated for by the reduced fuel tankage requirement. This is because combustion performance is not a particularly strong function of mixture ratio. 


\section{Propellant Selection}

Historically, low-thrust engine systems are based on storable, toxic mono- and bipropellants. These preferences arose mainly from concerns related to the designing for maximum performance and minimum weight, instead of designing for minimum cost, considering ecological and other important constraints. However, the use of very toxic and hazardous (for both, environment and personnel) propellants must be avoided, as much as possible and, in addition, currently cost is becoming one of the main concerns.

The criteria for selecting one propellant in preference to another include several factors: toxicity, ecological effects, performance, volumetrics, system sensitivity, complexity/reliability, development time, cost, and compatibility. Tables 2 and 3 list some interesting properties of unsymmetrical dimethyl-hydrazine (UDMH), $\left(\mathrm{CH}_{3}\right)_{2} \mathrm{NNH}_{2} ; 90 \%$ concentrated hydrogen peroxide (HTP90); nitrogen tetroxide (NTO), $\mathrm{N}_{2} \mathrm{O}_{4}$; and water, $\mathrm{H}_{2} \mathrm{O}$, which was included only for comparison.

The properties shown in Tab. 2 are: $\mathcal{M}$, molar mass; $\rho$, mass density; $T$, temperature; $H_{v}$, heat of vaporization; $c_{p}$, specific heat at constant pressure; $\mu$, dynamic viscosity; and $p_{v}$, vapor pressure. The tabled values of $H_{v}$ are measured at the normal boiling point (NBP) conditions, except for UDMH (1 bar, $298 \mathrm{~K}$ ). FP denotes the freezing point.

Propellant costs were omitted in Tab 3 once in a RCS the propellant quantities are very small, and the cost differences among these components are not so appreciable. The availability of each component is a more important aspect than its cost, for the present application. But availability will not be taken into account here, too.

Table 3: Handling and safety properties of the studied liquid propellant components.

\begin{tabular}{|c|cccc|}
\hline $\begin{array}{c}\text { Propellant } \\
\text { component }\end{array}$ & Stability & $\begin{array}{c}\text { Handling } \\
\text { hazard }\end{array}$ & Storability & Corrosion \\
\hline \hline UDMH & Good & Toxic & Good & $\begin{array}{c}\text { Slightly } \\
\text { corrosive }\end{array}$ \\
HTP90 & $\begin{array}{r}\text { Decomp. at } \\
140^{\circ} \mathrm{C}\end{array}$ & Flammable & Good & Corrosive \\
NTO & $\begin{array}{r}\text { Function of } \\
\text { temperature }\end{array}$ & Very toxic & Good (dry) & Corrosive \\
Water & Good & Good & Good & None \\
\hline
\end{tabular}

\section{CHAMBER MATERIALS}

The most common material system currently used for radiation-cooled rockets is a niobium alloy with a fused silica coating for oxidation protection. However, significant amounts of fuel film cooling are usually required to keep the material below its maximum operating temperature of $1640 \mathrm{~K}$ (Ultramet, 2002). Elimination of the fuel film cooling requires a combustion chamber material that can operate in a passive, radiation-cooled mode, at temperatures ranging from 2200 to $2480 \mathrm{~K}$, for NTO/UDMH engines (Schoenman, 1995).

Table 2: General data of the studied liquid propellant components.

\begin{tabular}{|c|c|c|c|c|c|c|c|c|}
\hline Propellant & $\mathcal{M}$ & $\mathrm{FP}$ & NBP & $\rho(T)$ & $H_{v}$ & $c_{p}(T)$ & $\mu(T)$ & $p_{v}(T)$ \\
\hline component & $\mathrm{kg} / \mathrm{kmol}$ & K & K & $\mathrm{kg} / \mathrm{m}^{3}(\mathrm{~K})$ & $\mathrm{kJ} / \mathrm{kg}$ & $\mathrm{cal} / \mathrm{g}-\mathrm{K}(\mathrm{K})$ & centipoise & bar $(\mathrm{K})$ \\
\hline UDMH & 60.08 & 216 & 336 & $789(295)$ & 584 & $0.649(298)$ & $0.490(300)$ & $0.1300(289)$ \\
\hline НТР90 & 31.286 & 261.65 & 414.25 & 1387 (298) & 1629 & $0.663(298)$ & $1.158(298)$ & $0.0044(298)$ \\
\hline NTO & 92.016 & 261.95 & 294.30 & 1447 (293) & 413 & $0.367(290)$ & $0.423(293)$ & $0.9580(293)$ \\
\hline Water & 18.02 & 273.15 & 373.15 & $1000(293)$ & 2553 & $1.008(273)$ & $1.000(277)$ & $0.0689(312)$ \\
\hline
\end{tabular}

High-temperature, oxidation-resistant materials have been developed for radiation-cooled rockets, which permit an increase of 100-200 N.s/ $\mathrm{kg}$ in specific impulse. These materials, specifically iridium lined rhenium, have the thermal margin to allow long life rocket operation up to $2470 \mathrm{~K}$, which enables the reduction or elimination of fuel film cooling (Ultramet, 2002).

In addition to the operational temperature limits, the choice of the chamber materials must take into account their possible reactiveness with the combustion products. However, even with film cooling, which can lower the temperature of the combustion chamber walls, the oxidation of the walls can be a limiting factor in the cases where oxidizing combustion products are encountered. The use of film cooling also forms a chemically protective gas film which restricts the transport of the combustion products to the wall, thus reducing the rate of oxidation of the walls.

Since thrust chamber masses may be as little as $1 \%$ of the total propellant mass, it can be readily appreciated that a $1 \%$ loss in effective $I_{s p}$ due to the cooling technique employed could override any chamber mass comparisons made for different cooling techniques. For this reason, a number of potential performance loss factors should be carefully examined. Below only the influences of film cooling will be discussed.

\section{FILM-COOLING}

A typical film-cooled rocket engine for attitude control is shown schematically in Fig. 1, which was taken from (Stechman et al., 1969). The injector provides a 
high combustion efficiency gas core through propellant mixing and atomization. High combustion efficiency is attained in very short chamber lengths $\left(L^{*}\right.$ from 25 to 40 $\mathrm{cm}$ at low contraction ratios). The injector also provides a uniform, high-velocity fluid layer at the combustion chamber wall with maximum penetration to the chamber throat. This layer is sometimes called wall layer.

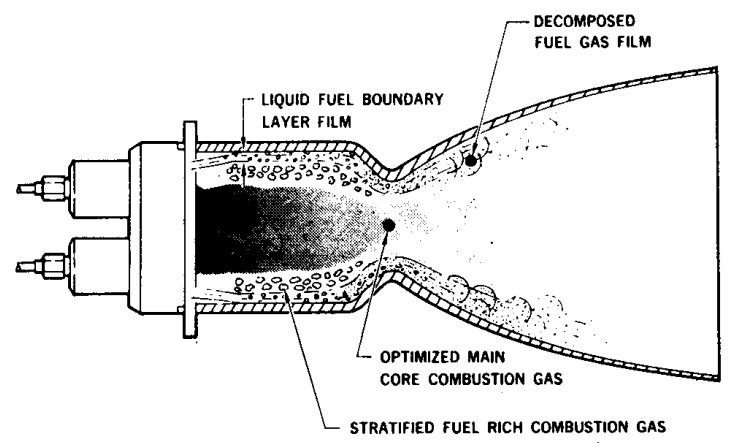

Figure 1: Film-cooled rocket engine.

The use of fuel film cooling in radiation-cooled chambers, in conjunction with mixture ratio stratification by the main injector elements, could lower the heat transfer to the combustor to such a degree that the wall temperatures encountered would be well below the structural and oxidation limit of the materials.

Film cooling has one great disadvantage: it degrades the engine performance (decrease its specific impulse) due to chemically incomplete burning, since a specific portion of the propellant in the wall layer burns with a great excess of one of its components, and there is a incomplete mixing of the film coolant with the core flow. In addition, film cooling decreases the specific mass of the propellant, since the fuel (usually used for internal cooling) has a lower specific mass than does the oxidizer. Therefore, internal film cooling is not as good as external radiation cooling. It is used mainly to supplement the more economical external cooling, when the latter cannot assure reliable shielding of the walls from the effects of the combustion products.

Besides degrading the engine performance film cooling has another drawback: some film coolant goes unreacted through the nozzle, proving to be a source of contamination in the plume. Therefore, elimination of the fuel film cooling will result in a cleaner burning engine and significantly higher specific impulse and, therefore, reduced launch costs and/or extended system life.

Note that a lower combustion temperature permits the use of simple injector head design, since the radiation cooling is enough for keeping the chamber walls within permissible limits.

\section{SYSTEM DESCRIPTION, MISSION AND REQUIREMENTS}

The baseline RCS has four engines with a common pressure regulated propellant feed system, which is composed by a container with the pressurant (helium, initially at 22 $\mathrm{MPa}$ ) and two spherical fuel and oxidizer tanks (to be kept at the nominal pressure of $1 \mathrm{MPa}$ ). This propulsion system integrates the control system of a satellite launcher, and has the function of provide reaction forces to control the vehicle around its roll axis during the flight of the second and third stages (Anon., 1992). The propellant is the combination $\mathrm{NTO} / \mathrm{UDMH}$, and the combustion pressure is $p_{c}=0.6 \mathrm{MPa}$. The engines work in pairs, with pulsed regime. The nominal vacuum thrust of each engine is $F=400 \mathrm{~N}$, and the cumulative operational time is $150 \mathrm{~s}$. The complete list of the nominal parameters for the mission and a single engine are shown in Tab. 4

Table 4: Nominal parameters for the mission and a single engine.

\begin{tabular}{|c|c|c|c|}
\hline parameter & symbol & value & unit \\
\hline engine vacuum thrust & $F$ & 400 & $\mathrm{~N}$ \\
\hline operational time & $t_{\text {oper }}$ & 150 & $\mathrm{~s}$ \\
\hline total impulse & $I_{t}$ & 60 & kN.s \\
\hline $\begin{array}{l}\text { combustion chamber } \\
\text { pressure }\end{array}$ & $p_{c}$ & 0.6 & $\mathrm{MPa}$ \\
\hline $\begin{array}{c}\text { global efficiency of the } \\
\text { thrust chamber }\end{array}$ & $\mathrm{h}_{t c}$ & 0.80 & \\
\hline $\begin{array}{c}\text { chamber contraction } \\
\text { area ratio }\end{array}$ & $\mathrm{e}_{c}=A_{c} / A_{t}$ & 5.56 & \\
\hline $\begin{array}{l}\text { nozzle expansion } \\
\text { area ratio }\end{array}$ & $\mathrm{e}_{e}=A_{e} / A_{t}$ & 50 & \\
\hline $\begin{array}{c}\text { contraction angle of } \\
\text { the chamber }\end{array}$ & $\mathrm{q}_{C}$ & 30 & degrees \\
\hline $\begin{array}{c}\text { expansion angle of the } \\
\text { nozzle }\end{array}$ & $\mathrm{q}_{e}$ & 11 & degrees \\
\hline $\begin{array}{c}\text { characteristic length of } \\
\text { the combustion } \\
\text { chamber }\end{array}$ & $L^{*}$ & 0.33 & $\mathrm{~m}$ \\
\hline $\begin{array}{l}\text { propellant tank } \\
\text { pressure }\end{array}$ & $p_{t}$ & 1.0 & $\mathrm{MPa}$ \\
\hline $\begin{array}{l}\text { initial pressure at } \\
\text { pressurant container }\end{array}$ & $p_{p v}$ & 22.0 & $\mathrm{MPa}$ \\
\hline pressurant & $\mathrm{He}$ & helium & \\
\hline
\end{tabular}

\section{COMPARATIVE ANALYSIS}

System evaluation criteria in the study were based on mass- and volume-performance, thermal constraints, and system sensitivities derived from analysis of propellant compositions.

In order to obtain the necessary data for comparing the proposed (HTP90/UDMH) and the original (NTO/UDMH) RCS, basically three computer programs were used. The thermochemical properties after the propellant combustion were determined with the program described in (Gordon and McBride, 1994), assuming shifting equilibrium along the thrust chamber. Note: unless explicitly noted, the used values correspond to the theoretical ones. The performance indices were calculated with a program normally used for propellant selection of pressure-fed propulsion systems (Oliveira, 2000a). The heat fluxes and the wall equilibrium temperatures were determined by a separate program. 


\section{Bulk Mass Density and Combustion Temperature}

The influence of mixture ratio $K_{m}$ on the bulk mass density $\rho_{p}$ and on the combustion chamber temperature $T_{c}$, at a chamber pressure $p_{c}=0.6 \mathrm{MPa}$, for bipropellant combinations of the studied components is shown in Fig. 2.
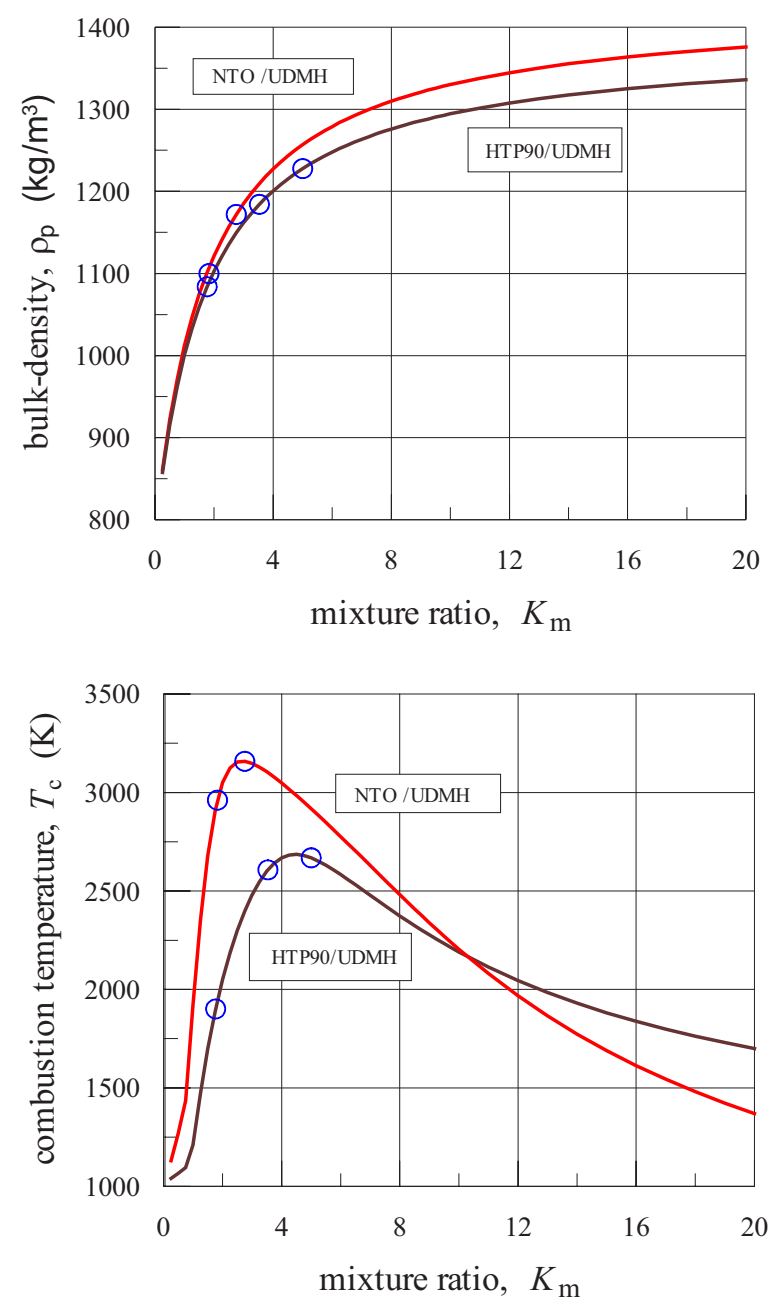

Figure 2: Bulk mass density and combustion temperature for $\mathrm{NTO} / \mathrm{UDMH}$ and HTP90/UDMH combinations at different propellant mass mixture ratios (the circles point out interesting mixture ratios).

The combustion process including hydrogen peroxide gives a relatively low adiabatic combustion temperature, which implies in less severe thermo-structural requirements. This means either reduced requirement for cooling the thrust chamber, or simply that low-cost materials could be used instead for the thrust chamber walls (while using film cooling).

\section{Performance Parameters}

A roll control system is an auxiliary propulsion system. As such, it has a propellant load small enough compared to the entire vehicle that the vehicle gross mass does not change appreciably during the system's firing and no significant translational velocity increment results. The mission of such a system is defined either by the thrust level and the duration of firing or, in equivalent terms, by the total impulse and the thrust level (Oliveira, 2000a).
The mass-performance of auxiliary propulsion systems is given in terms of the ratio of total impulse $\left(I_{t}\right)$ to system mass $\left(M_{s}\right)\left(\right.$ Oliveira, 2000a), i.e., $A \equiv I_{t} / M_{s}$.

The volume-performance of an auxiliary propulsion system can be evaluated by the density-impulse $\left(I_{d} \equiv \rho_{p} c\right.$, where $c$ is the effective exhaust velocity) obtained with the propellant combination (Oliveira, 2000a). Note that $I_{t}=F t_{\text {oper }}=V_{p} \rho_{p} c=V_{p} I_{d}$, where $t_{\text {oper }}$ is the operational time, and $V_{p}$ is the propellant volume. Thus, for a fixed total impulse, a higher $I_{d}$ implies in a lower $V_{p}$, which, in turn, means lower tank material mass, and lower mass of pressurant.

Figure 3 presents the mass- and volumeperformances for systems with propellant combinations $\mathrm{NTO} / \mathrm{UDMH}$ and HTP90/UDMH, for a large range of mass mixture ratios. These results indicate that both propellant combinations could attain almost equivalent volume-performances. However, the use of NTO could yield rather better mass-performance than HTP90.

\section{Equilibrium Temperatures}

The equilibrium temperatures reached by the walls of a refractory metal thrust chamber cooled only by radiation to the surroundings may be expressed in simplified form by the familiar steady-state equation

$$
\dot{q}_{t}=\dot{q}_{r}+\dot{q}_{c}=\varepsilon_{e} \sigma\left(T_{w}^{4}+T_{a m b}^{4}\right),
$$

where $\dot{q}_{t}, \dot{q}_{c}$ and $\dot{q}_{r}$ denotes, respectively, the total, convective and radiant heat transfer rates; $\varepsilon_{e}$ is the thermal emissivity of the external surface of the thrust chamber; $\sigma$ is the Stefan-Boltzmann constant; $T_{w}$ is the wall temperature; $T_{a m b}$ is the effective heat sink temperature (or the temperature of ambient exterior to the engine).

A graphical presentation of this relationship for NTO/UDMH and HTP/UDMH systems is shown in Fig. 4, where the convective heat-transfer coefficients were determined from equations by Bartz (Bartz, 1957), and the radiant heat flux rates were determined in accordance with the method described by (Vasiliev, 1993, Chap. 11). The adopted value for wall emissivity was $\varepsilon_{e}=0.8$. From these curves, it is obvious that, for this chamber pressure level $\left(p_{c}=0.6 \mathrm{MPa}\right)$, pure radiation cooling for an entire engine is unfeasible even for the HTP90/UDMH pair, unless it is used a more sophisticated wall material, such as a niobium alloy with a silica coating ${ }^{2}$.

\footnotetext{
${ }^{2}$ Note that, in principle, the calculated equilibrium wall temperatures are overestimated, since the Bart equations usually overestimate the heat flux rates at the throat, and the true combustion temperatures are lower than the theoretical values used here.
} 
TECNOLOGIA/TECHNOLOGY
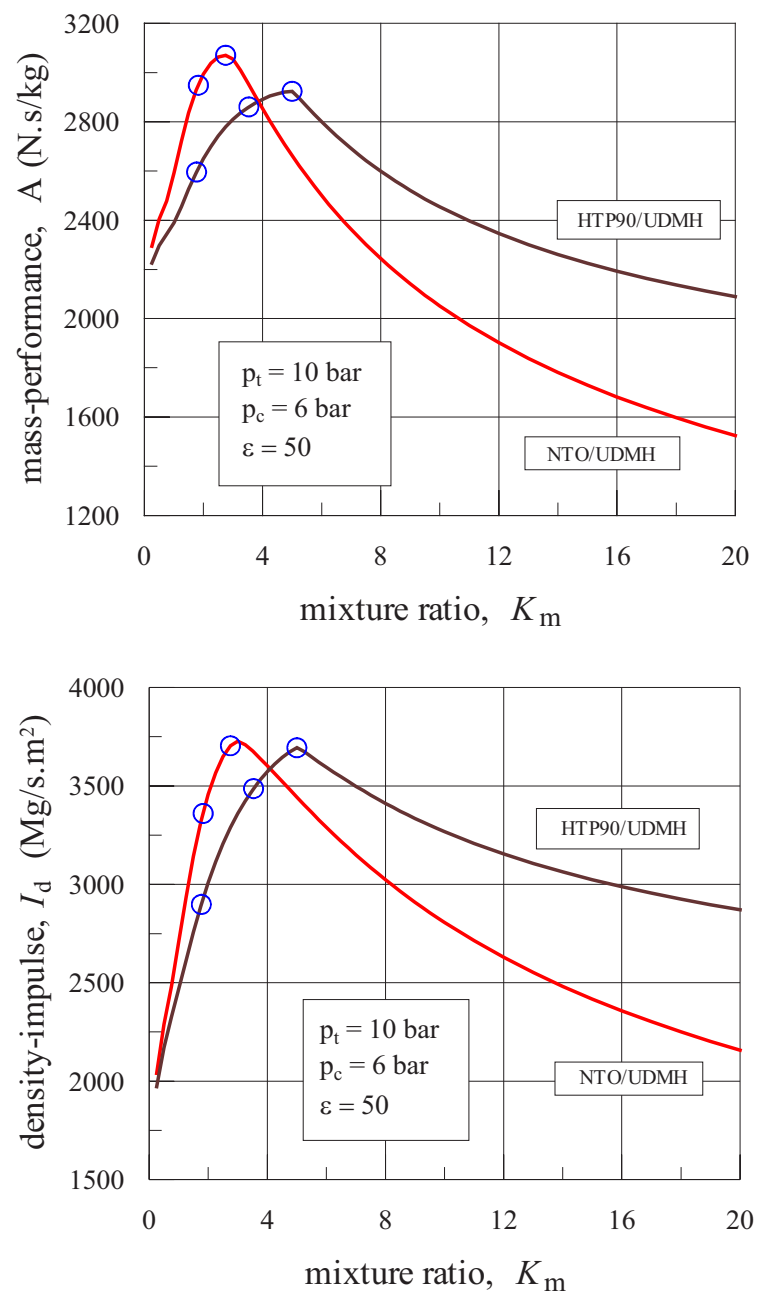

Figure 3: Influence of the propellant mass mixture ratio on mass- and volume-performance of NTO and HTP90 with UDMH (the circles indicate points of interest for further analysis).

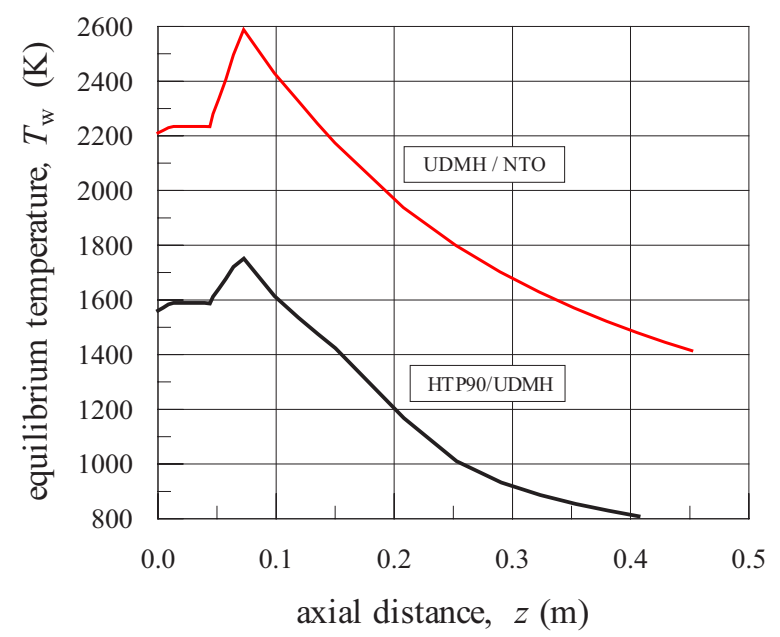

Figure 4: Axial behavior of the wall equilibrium temperatures for thin-walled radiation-cooled thrust chamber for equal volumes of oxidizer and fuel $\left(p_{c}=0.6 \mathrm{MPa}\right)$.
U. C. Oliveira and D. J. F. Villas Boas Substitution of NTO...

\section{Discussion of the Results}

The analysis of the results shown in Figs. 2 and 3 permit to speculate that mixture ratios other than for equal volumes of oxidizer and fuel could be of practical importance. This is the case of mixture ratios that give the better performance indices, and also the mixture ratio that gives three equal volume tanks (two for oxidizer, one for fuel) for the HTP90/UDMH pair. The points corresponding to these situations were plotted (small circles) on the previous curves, and the corresponding wall equilibrium temperatures are shown in Fig. 5.

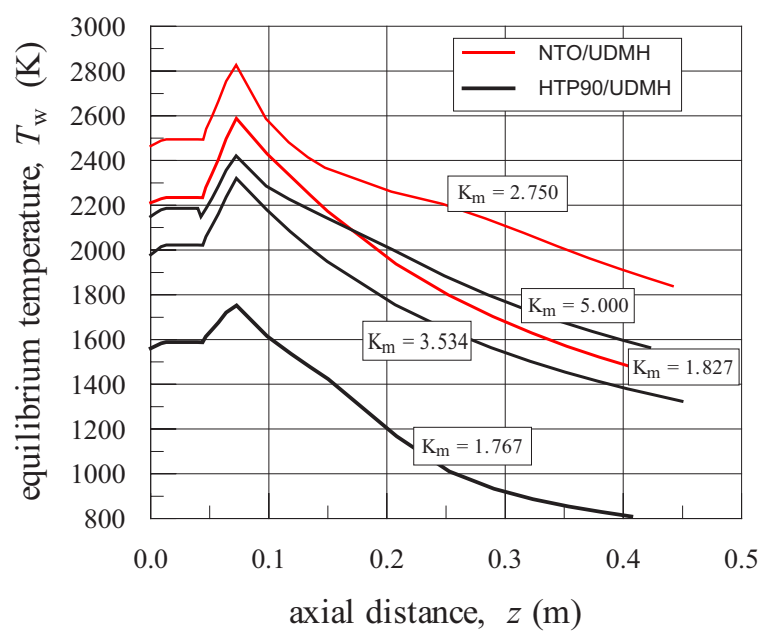

Figure 5: Wall equilibrium temperatures for radiationcooled thrust chambers at several mixture ratios $\left(p_{c}=0.6 \mathrm{MPa}\right)$

Table 5 summarizes previous results for the interesting values of mixture ratios. Indubitably, the performance levels for NTO/UDMH are higher than the HTP90/UDMH ones. However, comparing the equilibrium temperatures at points of maximum performance, it is seen that the value corresponding to $\mathrm{NTO} / \mathrm{UDMH}$ is $400 \mathrm{~K}$ higher. At these same points, the difference of combustion temperature of the pair $\mathrm{NTO} / \mathrm{UDMH}$ in relation to the pair HTP90/UDMH is of about $490 \mathrm{~K}$. Such difference increases to $1060 \mathrm{~K}$ at points corresponding to equal volumes of oxidizer and fuel (in this case, the difference equilibrium wall temperature is $840 \mathrm{~K}$.

In the other hand, for a fixed limit of temperature, it is possible to find a mixture ratio for the HTP90/UDMH pair, which has equal or superior performance levels than for the NTO/UDMH pair. This way, for a given chamber material, it is possible to use a less toxic propellant combination without loss of performance.

Results of heat transfer and equilibrium temperatures for cases with film-cooling will be not presented since the accuracy of the used calculation methods were not verified with test data, yet.

In the original RCS the film-coolant is the oxidizer (NTO). So, it is important note that, apparently, HTP90 has better film-coolant properties. HTP90 has higher heat of vaporization and specific heat at liquid phase than NTO. HTP90 still has a much lower vapor pressure than NTO; therefore HTP90 presents higher boiling 
temperature than NTO. However, NTO decomposes endothermally, while HTP90 decomposes exothermally.

\section{CONCLUSIONS}

This is a preliminary study of possible advantages due to the substitution of nitrogen tetroxide (NTO) for hydrogen peroxide solution (HTP) in a Roll Control System (RCS). The original RCS is a bipropellant, pressurized system, whose fuel is unsymmetrical dimethyl-hydrazine (UDMH) and whose oxidizer is NTO. It is used in satellite launch vehicles launched from a tropical base.

The NTO, being an extremely toxic and carcinogenic substance, requires special care in its handling. It has a boiling temperature $\left(21.15^{\circ} \mathrm{C}\right.$, at $\left.0.1 \mathrm{MPa}\right)$ lower than the environmental average temperatures at tropical bases, which could be above $32^{\circ} \mathrm{C}$. This becomes necessary to cool the tank of NTO during the vehicle integration process and the entire period in which the vehicle remains at the launching pad.

On the other hand, HTP is a stable, non-toxic substance and, since basic precautions be taken, it can be handled as if it were pure water. HTP has a much higher boiling point $\left(141.2^{\circ} \mathrm{C}\right.$ for a $90 \%$ concentration) than the NTO, and still presents a much lower vapor pressure. In a similar way as NTO, HTP also forms a hypergolic pair with UDMH. Another additional advantage results from the lower adiabatic combustion temperature obtained with HTP $(2680 \mathrm{~K}$ for a $90 \%$ concentration), in comparison with that one obtained with NTO (3150 K).

The initial analysis conducted on the NTO/UDMH $400 \mathrm{~N}$ engine shows that this engine could capable of operation with HTP90 without significant modification in the design and/or qualification base of the engine. The oxidizer change brings about a satisfactory performance and operation at temperature levels well below that ones encountered in the similar NTO/UDMH system. Even with a decrease in liquid film cooling, the HTP90/UDMH engine would present a substantial reduction of the combustion chamber temperature, and give approximately the same performance level of the original NTO/UDMH engine. A detailed analysis, and tests, could indicate that additional modifications are necessary. However, at first, the only change required for the new thruster is in the injector orifice dimensions. In conclusion: after analyzing advantages and drawbacks, this study indicates the economical, technical, and ecological convenience of the substitution of NTO by HTP90 in the roll control system of satellite launch vehicles.

Table 5: Influence of oxidizer nature and mixture ratio on equilibrium temperature and performance.

\begin{tabular}{|l|c|c|c|c|c|c|c|c|}
\hline oxidizer, condition & $K_{m}$ & $A$ & $I_{d}$ & $I_{v a c}$ & $I_{s p}$ & $\rho_{p}$ & $T_{c}$ & $T_{w}$ \\
& & $\mathrm{~N} \cdot \mathrm{s} / \mathrm{kg}$ & $\mathrm{kN} \cdot \mathrm{s} / \mathrm{m}^{3}$ & $\mathrm{~N} \cdot \mathrm{s} / \mathrm{kg}$ & $\mathrm{N} \cdot \mathrm{s} / \mathrm{kg}$ & $\mathrm{kg} / \mathrm{m}^{3}$ & $\mathrm{~K}$ & $\mathrm{~K}$ \\
\hline \hline NTO, $V_{o}=V_{f}$ & 1.827 & 2948.4 & 3359.9 & 3199.1 & 3036.8 & 1099.8 & 2960.96 & 2588.96 \\
NTO, max. perf. & 2.750 & 3070.2 & 3703.6 & 3326.8 & 3160.5 & 1171.9 & 3157.97 & 2826.79 \\
\hline HTP90, $V_{o}=V_{f}$ & 1.767 & 2595.5 & 2897.8 & 2814.7 & 2673.8 & 1083.8 & 1900.83 & 1751.87 \\
HTP90, $V_{o}=2 V_{f}$ & 3.534 & 2860.2 & 3486.2 & 3099.2 & 2944.0 & 1184.2 & 2606.91 & 2320.95 \\
HTP90, max. perf. & 5.000 & 2923.7 & 3693.4 & 3166.8 & 3008.5 & 1227.7 & 2668.21 & 2421.43 \\
\hline
\end{tabular}




\section{REFERENCES}

Andrews, D., 1990, “Advantages of Hydrogen Peroxide as a Rocket Oxidant," Journal of the British Interplanetary Society, Vol. 43, July, pp. 319-328.

Anon., 1992, Liquid Propulsion Roll Control System for the VLS - Specification. Technical Report No. 590370000/B3001, VLS System Engineering Group, Instituto de Aeronáutica e Espaço, Oct.

Bartz, D. R., 1957, "A simple equation for rapid estimation of rocket nozzle convective heat transfer coefficients," Jet Propulsion, 27, 49-51.

Bloom Jr., Ralph; Davis Jr., Noah S.; Levine, Samuel D., 1950, "Hydrogen Peroxide as a Propellant," Journal of the American Rocket Society, No. 80, pp. 3-17, March.

Gordon, S.; and McBride, B. J., 1994, CET93 and CETPC: An Interim Updated Version of the NASA Lewis Computer Program for Calculating Complex Chemical Equilibria With Applications. NASA TM4557.

Hurlbert, E.; Applewhite, J.; Nguyen, T.; Reed, B.; Baojiong, Z.; and Yue, W., 1998, "Nontoxic Orbital Maneuvering and Reaction Control Systems for Reusable Spacecraft". Journal of Propulsion and Power, Vol. 14, No. 5, September-October.

Jeff, Martin, 1998, "Hydrogen Peroxide — The Safe Supply and Handling of HTP." 1st International Hydrogen Peroxide Propulsion Conference, July 29-31, University of Surrey, England.

London III, John R., 1994, LEO on the Cheap Methods for Achieving Drastic Reductions in Space Launch Costs, Maxwell AFB, Air University Press.

Oliveira, U. C., 2000a, Performance of Auxiliary and Upper-Stage Pressure-Fed Propulsion Systems. Paper IAF-00-S.2.05, 51st International Astronautical Congress, 2-6 Oct., Rio de Janeiro, Brazil.

Oliveira, U. C., 2000b, Study of Propellants for Pressure-Fed Propulsion Systems. Paper S24P07, 8th Brazilian Congress of Thermal Engineering and Sciences, October 3-6, Porto Alegre, Brazil.

Oliveira, U. C., 2002, Revisão Crítica do Sistema de Controle de Rolamento do VLS-1. Work in progress (to apear as Internal Report of Institute of Aeronautics and Space).

Schoenman, Len, 1995, “4000F Materials for LowThrust Rocket Engines, Journal of Propulsion and Power, pp. 1261-7, Vol. 11, No. 6, November-December.

Stechman, R. Carl; Oberstone, Joelee; Howell, J. C., 1969, "Design Criteria for Film Cooling for Small Liquid-Propellant Rocket Engines," J. Spacecraft and Rockets, Vol. 6, No. 2, pp. 97-102, February.

Taylor, Barry N., 1995, "Guide for Use of the International System of Units (SI)," NIST Special Publication 811, 1995 Edition, National Institute of Standards and Technology.

Truax, Robert, 1999, "The Future of Earth-To-Orbit Propulsion." Aerospace America, pp. 34-36, January.

Ultramet Co., 2002, Iridium/Rhenium (Ir/Re) Rockets, http: //www.ultramet.com.

Vasiliev, A. P. et al., 1993, Fundamentals of Theory and Calculation of Liquid Rocket Engines, Part 2. Vischaia Shkola, Moscow. (In Russian). 